\title{
Hookpod-mini: a smaller potential solution to mitigate seabird bycatch in pelagic longline fisheries
}

\author{
David Goad ${ }^{1, *}$, Igor Debski $^{2}$, Joanne Potts ${ }^{3}$ \\ ${ }^{1}$ Vita Maris Limited, Papamoa, 3118, New Zealand \\ ${ }^{2}$ Department of Conservation, Wellington, 6011, New Zealand \\ ${ }^{3}$ The Analytical Edge Statistical Consulting, Tasmania, 7052, Australia
}

\begin{abstract}
Hookpods are an emerging technology designed to reduce seabird bycatch in pelagic longline fisheries. Hookpod-minis were trialled in the New Zealand surface longline fishery in 2016-2017 during short-term experimental (20 longline sets) and longer-term operational (110 longline sets) trials. Two sets of experimental trials were conducted. The first compared snoods fitted with Hookpod-minis with a tori line to unweighted snoods with a tori line. The second compared snoods fitted with Hookpod-minis as a stand-alone mitigation measure to weighted snoods in combination with a tori line. All gear, across both trials, was set at night. Operational trials compared snoods fitted with Hookpod-minis and tori lines to standard mitigation requirements for unweighted gear and tori lines, with all gear set at night. Both sets of trials demonstrated that Hookpod-minis fit easily into fishing operations, do not reduce target species catch rate, and may reduce seabird bycatch to low levels. Our findings suggest that Hookpod-minis as a stand-alone mitigation measure are as effective, or more effective, than current bycatch mitigation measures including the combination of line weighting and tori lines.
\end{abstract}

KEY WORDS: Mitigation $\cdot$ Pelagic longline $\cdot$ Seabird bycatch $\cdot$ Tori line

\section{INTRODUCTION}

Due to the continued threat to albatross and other pelagic seabirds posed by longline fishing (Croxall et al. 2012, BirdLife International 2015), there is a continuing drive to find new operationally simple solutions to effectively mitigate seabird bycatch in demersal and pelagic longline fisheries. This is best exemplified by recent efforts to design and test new innovative technologies (Ryan \& Watkins 2002, Gilman et al. 2003, Robertson et al. 2013, Sullivan et al. 2018). It has proved both technically and politically challenging to take these new technologies from the engineering phase and at-sea testing through to securing regulatory support and widespread uptake onboard vessels. The Hookpod is a polycarbonate capsule that encases the point and barb of baited pelagic longline hooks to prevent

\footnotetext{
${ }^{*}$ Corresponding author: goad.dave@gmail.com
}

seabirds from becoming hooked and drowning during line-setting operations. The device contains a pressure-release mechanism that opens the pod and releases the baited hook at a predetermined depth. These devices have been in development since 2005, with iterative improvements in design resulting from trials at sea and feedback from fishers and experts in the field. Similarly, an underwater bait setter took $8 \mathrm{yr}$ and US \$1.1 million to refine (Robertson et al. 2015).

Between 2010 and 2015, operational trials of the Hookpod-LED were completed in Australia, Brazil, and South Africa onboard pelagic longliners targeting tuna Thunnus spp. and swordfish Xiphias gladius. These trials demonstrated that the Hookpod-LED (a larger version of Hookpod with a light-emitting diode incorporated in the housing), which released baited hooks at $10 \mathrm{~m}$ depth (Fig. 1), was effective at reducing

() The authors 2019. Open Access under Creative Commons by Attribution Licence. Use, distribution and reproduction are unrestricted. Authors and original publication must be credited. 


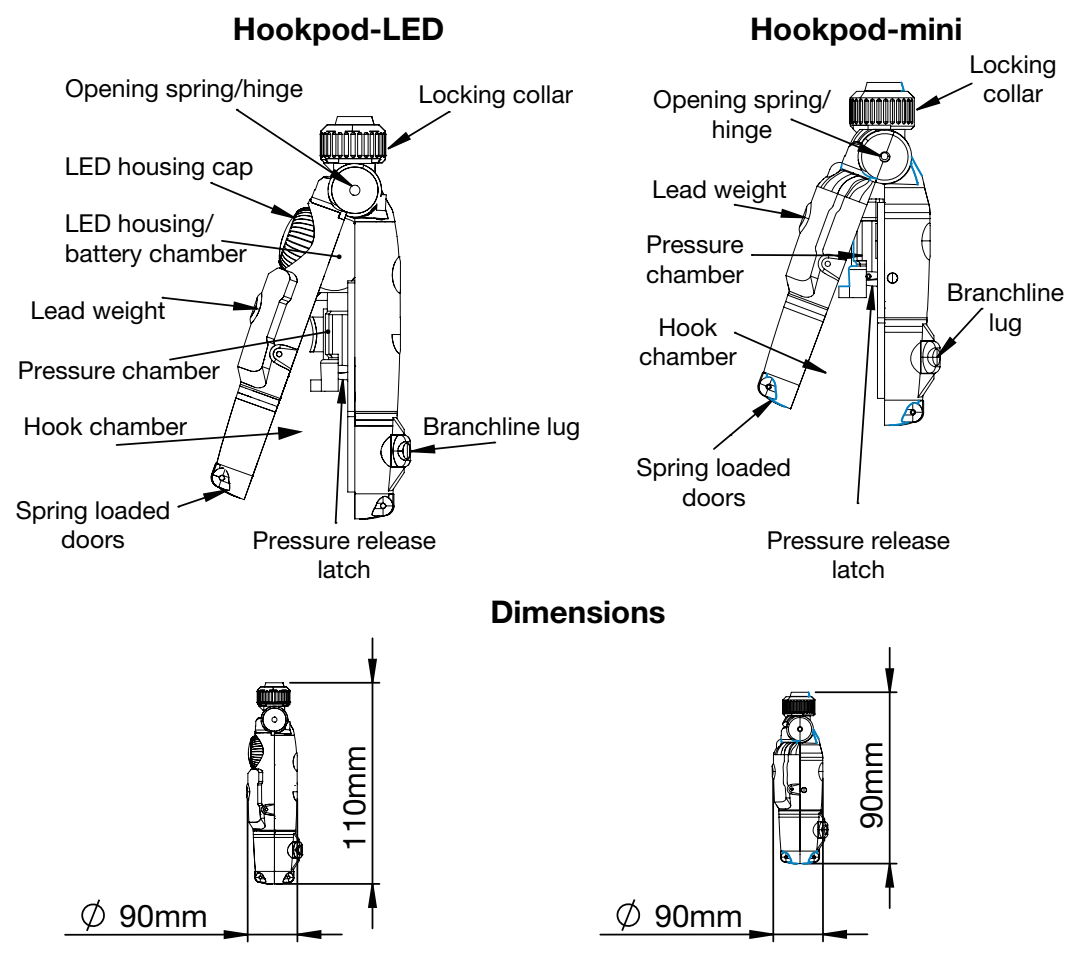

Fig. 1. Relative size and features of the Hookpod_LED and Hookpod-mini

Longer-term operational trials were conducted as part of normal fishing operations and the skipper recorded extra information on Hookpod performance in addition to that required in his government-issued logbooks.

\subsection{Hookpod design}

Like the original Hookpod-LED, the Hookpod-mini is a polycarbonate capsule that is attached to a monofilament branchline. During line setting, the baited hook is loaded into the Hookpod-mini to encase the point and barb of the hook, preventing seabirds from becoming hooked as they scavenge baited hooks at the stern of vessel. A pressure-release mechanism releases the hook at a predetermined depth (see Sullivan et al. 2018 for full operational details). However, the Hookpod-mini does not contain an LED (autonomous light source) and the accompanying elec-

seabird bycatch to low levels, did not reduce catch rates of target species, and was safe, durable, and operationally simple to use (Sullivan et al. 2018).

Here, we describe at-sea trials of a new version of the Hookpod that is smaller, simpler, and cheaper and does not contain an autonomous (LED) light source (sensu Sullivan et al. 2018).

\section{MATERIALS AND METHODS}

This research consists of multiple data sets, both experimental and operational, collected on 3 vessels operating in the shallow-set New Zealand surface longline fishery. Vessels were typical of those in the fleet: 20 to $21 \mathrm{~m}$ overall length with steel hulls, stabilizer arms, and full shelter decks. Short-term experimental trips were conducted with a dedicated observer onboard who observed all experimental hooks during line setting and hauling.

For Hookpod-mini and control treatments, the fish caught (both target and non-target species) were identified to the species level. In addition, seabird abundance counts were made within $100 \mathrm{~m}$ of the vessel at least every $2 \mathrm{~h}$ whilst fishing, when visibility allowed. All seabird bycatch was recorded to species level. trical circuitry and is therefore 20\% smaller and 25\% lighter than the original Hookpod-LED (Fig. 1). A Hookpod-mini weighs $48 \mathrm{~g}$ and has a $15 \mathrm{~g}$ lead weight incorporated into the housing. The Hookpodmini was developed to provide a smaller, cheaper mitigation option that maintains flexibility for fishermen to choose whether to add chemical lightsticks or electric lights to snoods on a set-by-set basis.

\subsection{Experimental data}

Across all vessels, Hookpod-minis were positioned on the hook during line setting, until the pressurerelease mechanism opened the pod and released the baited hook. Having the weight of the Hookpod-mini positioned at the hook on setting is important, because the closer a weight is to the hook, the more rapidly it sinks (Robertson et al. 2010, Robertson \& Candy 2014).

\subsubsection{Vessel A}

A short-term experimental data set consisting of 8 longline sets was collected in September 2016. The trial was conducted off the north-east coast of New 
Zealand, targeting bigeye tuna Thunnus obesus and consisted of 2 treatments: (1) an unweighted control and (2) Hookpod-mini snoods, both with a tori line and both set at night. Approximately half the control snoods had a $60 \mathrm{~g}$ weighted swivel at the clip, and half had an unweighted swivel at the clip. These configurations can both be considered as unweighted, as a weighted swivel positioned $13 \mathrm{~m}$ from the baited hook (at the clip) will have negligible effect on the sink rate of the hook (Robertson et al. 2010). The Hookpod-minis were positioned on the snood at different positions between sets, ranging from 1.8 to $1.2 \mathrm{~m}$ from the hook. All snoods consisted of $2 \mathrm{~mm}$ diameter monofilament nylon of 10 to $13 \mathrm{~m}$ length with a 16/0 circle hook. Over the course of the trip, $\sim 5 \%$ of hooks were replaced with $\mathrm{J}$ hooks at a relatively even ratio between the 2 treatments. All hooks were baited with whole arrow squid Notodarus spp. The 2 treatments were set in 4 alternate blocks, with the first treatment randomly assigned.

\subsubsection{Vessel B}

Under Special Permit (654), 2 treatments were deployed for 12 sets in July 2017 off the south-west coast of New Zealand targeting southern bluefin tuna Thunnus maccoyii. Treatments compared target catch rates and seabird bycatch rates on snoods with Hookpod-minis without a tori line deployed to control snoods of weighted gear with a tori line deployed. All gear was set at night. Hookpod-minis were positioned on the snood $0.5 \mathrm{~m}$ from the hook, and control branchlines had $60 \mathrm{~g}$ GloLeads placed $1 \mathrm{~m}$ from the hook. Due to the operational challenges of deploying and retrieving tori lines partway through line-setting, the 2 treatments were set in 2 blocks, with the first treatment randomly assigned. Similarly, issues with the use of a tori line in high-wind conditions resulted in the skipper choosing to not deploy a tori line for 4 of the 12 control sets.

\subsubsection{Vessel C}

Trials on the third vessel targeting bigeye tuna T. obesus were conducted off the north-east coast of New Zealand during February 2017 solely for the purpose of collecting sink rate data on an additional vessel. All snoods had $38 \mathrm{~g}$ weighted swivels positioned at $0.5 \mathrm{~m}$ from the hook.

\subsection{Sink rate}

Time depth recorders (TDRs) (Star Oddi DST) were attached in near equal proportions for different treatments at $0.5 \mathrm{~m}$ from the hook. TDR snoods were all deployed mid-basket and mid-section between the ends of the longline. The time snoods were clipped onto the longline was recorded on a digital watch and was used to identify start time $(0 \mathrm{~s})$ on TDR records. This start time allowed for time and speed to be used to calculate distance behind the vessel. Baited hooks were cast sideways, outside the propeller wash. TDR data were calibrated to read $0 \mathrm{~m}$ prior to deployment, and temperatures used to adjust pressure records and calculate depth immediately after immersion were estimated from first stable temperature records above the thermocline. On Vessel A, Hookpod-minis were positioned $1.8 \mathrm{~m}$ from the hook on TDR snoods and compared to unweighted gear. A further trip was undertaken onboard Vessel C to collect sink rate data comparing Hookpod-minis on the hook with $38 \mathrm{~g}$ weighted swivels at $0.5 \mathrm{~m}$ from the hook and $60 \mathrm{~g}$ GloLeads at $1 \mathrm{~m}$ from the hook.

\subsection{Operational data}

A longer-term operational data set consisting of 110 sets over a 10 mo period from September 2016 to July 2017 was also collected on Vessel A. During this period, the vessel operated off the east coast of New Zealand's North Island for 96 sets and in May 2017 off the west coast of the South Island for 14 sets. Hookpod-minis were fitted to approximately half the gear and were set in a single block. The remaining snoods consisted of standard unweighted gear, as described in Section 2,2.1. The vessel operated under the New Zealand requirements of night setting (for unweighted gear) and use of a $75 \mathrm{~m}$ aerial extent tori line (New Zealand Gazette 2014). Unlike the other data sets reported here, no observer was onboard for these operations and these data did not include the collection of target and non-target catch rates. The skipper and crew simply recorded the number of pods that 'failed' and the number of seabirds captured on standard and Hookpod-mini snoods for each set.

\subsection{Assessing fish catch rates}

To identify trends and patterns in the data, boxplots summarising the median, interquartile range, and 
tails of the distribution of catch rates between treatments for each vessel were visually inspected prior to our analysis. These figures are not presented here (authors' unpubl. data).

Given the relatively simple sampling design and small sample sizes of 8 sets on Vessel A and 12 on Vessel B, complex models such as generalised linear mixed models that could account for between-set correlation within each vessel were not used. Instead, to ensure a robust analysis, we conducted a paired $t$-test for each set of observations based on Hookpodmini versus 'control', noting that the control for each vessel differed. Analysis was conducted in the statistical software program R (v.3.4.0, www.cran.r-project. org).

Individual fish species caught were grouped into family cohorts, as data were too sparse for singlespecies analyses. Family cohorts were: 'Target tuna', containing bigeye tuna (Vessel A) and southern bluefin tuna (Vessel B); 'All tuna', containing southern bluefin tuna, yellowfin tuna T. albacares, northern bluefin tuna $T$. orientalis, albacore $T$. alalunga, and bigeye tuna; 'Blue shark', containing blue shark Prionace glauca, and 'All sharks' containing blue shark as well as porbeagle shark Lamna nasus and mako shark Isurus oxyrinchu.

\section{RESULTS}

\subsection{Seabird assemblages and bycatch}

Vessel A fished on the north-east coast of the North Island and bird assemblages present were typical of the summer fishery. Maximum numbers of birds present around the vessel during hauling included 50 grey-faced petrels Pterodroma macroptera, 4 great albatrosses Diomedea spp., 2 Buller's albatrosses Thalassarche bulleri, 2 black-browed albatrosses $T$. melanophris, T. impavida, 3 flesh-footed shearwaters Puffinus carneipes, and 3 black petrels Procellaria parkinsoni. Birds were not seen directly interacting with the gear and spent most time astern feeding on discarded offal and baits. No birds were observed whilst setting, although visibility was poor for most sets.

Vessel B fished on the south-west coast of the South Island in winter and had a higher overlap with albatrosses. Maximum numbers of birds present around the vessel during hauling included 2 great albatrosses, 45 white-capped albatross T. steadi, 15 Buller's albatross, 10 black-browed albatross, 5 Salvin's albatross T. salvini, 20 Westland petrels Procellaria westlandica, 20 prions Pachyptila spp., 20 cape petrels Daption capense, and 5 storm petrels. Birds were not seen directly interacting with the gear and spent most time astern feeding on discarded offal and baits. During setting, despite the large moon, cloud cover often restricted visibility. However, albatrosses and cape petrels were observed behind the vessel during 4 sets.

Zero seabird mortalities were recorded during the 8 experimental sets on Vessel A, which comprised 3274 control hooks and 2882 Hookpod-mini hooks. Two white-capped albatross were killed on Vessel B: one on Hookpod-mini snoods and one on the control snoods. This gave a capture rate of 0.2 per 1000 hooks for the 4982 Hookpod-mini snoods and 0.18 per 1000 hooks for the 5462 control snoods.

In the 10 mo operational trials on Vessel A, a total of 16 seabird mortalities were recorded: 13 on control snoods and 3 on Hookpod-mini snoods at a rate of 0.248 and 0.079 per 1000 hooks, respectively. Six birds were entangled in the snoods: 2 on the Hookpod-mini snoods and 4 on control snoods. All other birds were hooked in the bill or wing. Nine of the 16 dead birds were caught during 14 sets off the west coast of the South Island. A single live bird was caught and released alive, off the west coast of the South Island. These data were not recorded to species level by the crew and were simply logged as seabird mortality (Table 1).

\subsection{Assessing fish catch rate}

As is typical, pelagic longline catches were 'patchy' and often concentrated in relatively short sections of

Table 1. Skipper-recorded effort and bycatch during operational trials on Vessel A. Dates are d/mo/yr

\begin{tabular}{|c|c|c|c|c|c|c|c|c|}
\hline \multirow[t]{2}{*}{ Timing } & \multirow[t]{2}{*}{ Area fished } & \multirow[t]{2}{*}{ Sets } & \multirow{2}{*}{$\begin{array}{l}\text { Hookpod } \\
\text { mini snoods }\end{array}$} & \multirow{2}{*}{$\begin{array}{l}\text { Control } \\
\text { snoods }\end{array}$} & \multicolumn{2}{|c|}{-Hookpod-mini-_ } & \multicolumn{2}{|c|}{ Control gear } \\
\hline & & & & & Dead birds & Live birds & Dead birds & Live birds \\
\hline $18 / 9 / 16-9 / 4 / 17$ & East coast & 62 & 24250 & 25150 & 2 & 0 & 5 & 0 \\
\hline $18 / 4 / 17-11 / 5 / 17$ & West coast & 14 & 4610 & 7190 & 1 & 0 & 8 & 1 \\
\hline $23 / 5 / 17-3 / 8 / 17$ & East coast & 34 & 8250 & 22150 & 0 & 0 & 0 & 0 \\
\hline
\end{tabular}



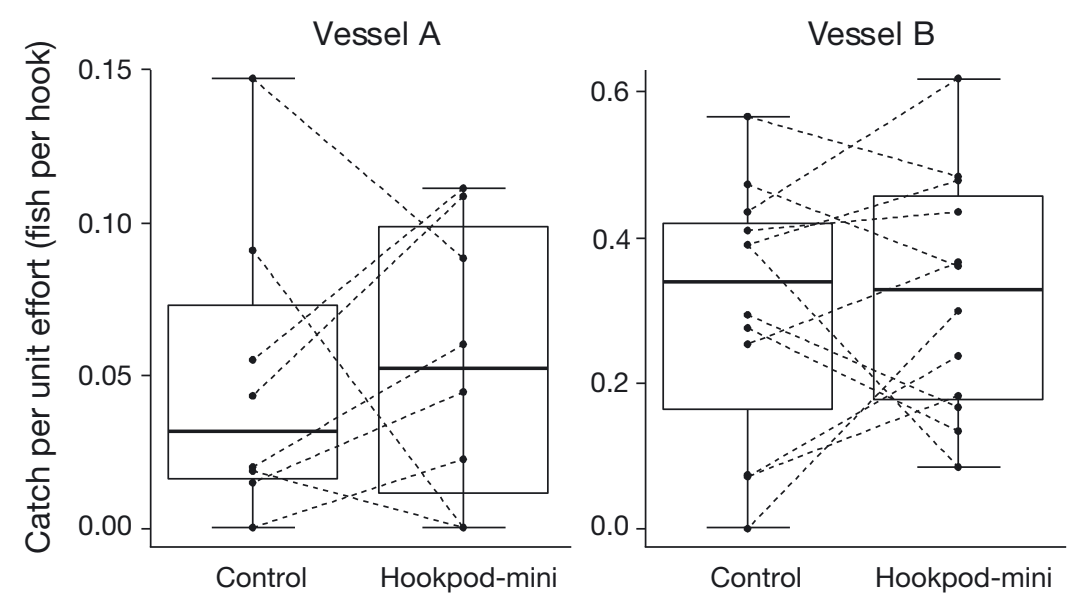

Fig. 2. Boxplot of catch rate of target tuna on Hookpod-minis and control snoods. Boxes represent the interquartile range with the median value as a dark line within the box. Horizontal lines outside the boxes highlight the maximum and minimum data points. The dotted lines in the boxplots represent the relationship between paired observations in each set

Table 2. Recorded catch during experimental trials of Hookpod-mini snoods and control snoods on Vessels A and B

\begin{tabular}{|c|c|c|c|c|}
\hline & \multicolumn{2}{|c|}{- Vessel A } & \multicolumn{2}{|c|}{ — Vessel B } \\
\hline & Minipods & Unweighted & Minipods & Gloleads \\
\hline No. of branchlines & 2882 & 3274 & 4982 & 5462 \\
\hline \multicolumn{5}{|l|}{ No. of fish } \\
\hline Albacore & 14 & 16 & 2 & 7 \\
\hline Bigeye & 19 & 15 & 0 & 0 \\
\hline Southern bluefin & 10 & 7 & 214 & 192 \\
\hline Northern bluefin & 2 & 0 & 0 & 0 \\
\hline Yellowfin & 1 & 0 & 0 & 0 \\
\hline Swordfish & 3 & 3 & 1 & 3 \\
\hline Blue shark & 64 & 73 & 102 & 142 \\
\hline Porbeagle shark & 3 & 3 & 21 & 23 \\
\hline Mako shark & 5 & 6 & 1 & 4 \\
\hline Unidentified & 1 & 4 & 1 & 3 \\
\hline \multicolumn{5}{|l|}{ Bycatch } \\
\hline Fur seal & 0 & 0 & 2 & 4 \\
\hline $\begin{array}{l}\text { White-capped } \\
\text { albatross }\end{array}$ & 0 & 0 & 1 & 1 \\
\hline
\end{tabular}

'Target tuna' and all other family 'cohorts' (Table 3).

\subsection{Replacement rate of Hookpod-minis}

The rate of lost/broken pods and failed pods was identical between experimental trials conducted on vessels $\mathrm{A}$ and $\mathrm{B}$ and similar to those recorded in the longer-term operational trials (Table 4). Failed pods represent all forms of malfunctioning pods, e.g. pod failing to open. During the experimental trials, the total replacement rate (failed plus lost/broken pods) was $0.92 \%$ compared to a rate of $1.05 \%$ for the 10 mo operational sampling period.

\subsection{Sink rate}

TDR records were collected across 6 sets, 3 vessels and 4 weighting configurations (Table 5). To focus on the practical application of sink rate profiles, here we present TDR results in conjunction with setting speed data in order to estimate the depth of hooks at given distances behind the vessel, as well as considering time to a given depth (Table 5). These data are relevant from a management perspective because they can be related to the performance of streamer lines in relation to the depth of baited hooks sinking at the stern of the vessel (see Melvin et al. 2013, 2014).

Hookpod-minis sank faster than unweighted gear to 2, 5 and $10 \mathrm{~m}$ depths the line. Boxplots for all family 'cohorts' suggest the distribution of catch rate between treatment types are overlapping and reveal large variability between vessel, set, and treatment, for example Target tuna (Fig. 2). All tuna, Blue shark and All sharks family cohorts are not presented here but demonstrated a similarly high degree of variability. This high variability in the catch data is further supported by the raw catch data (Table 2).

Paired $t$-tests indicate no significant differences in catch rates of target species between treatments for
Table 3. Paired $t$-test comparing catch rate on Hookpodminis with control snoods for all family cohorts

\begin{tabular}{|c|c|c|c|c|c|c|}
\hline & \multicolumn{3}{|c|}{- Vessel A- } & \multicolumn{3}{|c|}{ Vessel B } \\
\hline & $t$ & $\mathrm{df}$ & $\mathrm{p}$-value & $t$ & $\mathrm{df}$ & $\mathrm{p}$-value \\
\hline Target tuna & 1.05 & 14 & 0.31 & -0.27 & 22 & 0.79 \\
\hline All tuna & 0.42 & 14 & 0.68 & -0.16 & 22 & 0.88 \\
\hline Blue shark & 0.61 & 14 & 0.55 & 1.26 & 22 & 0.22 \\
\hline All sharks & 0.64 & 14 & 0.53 & 1.21 & 22 & 0.24 \\
\hline
\end{tabular}


Table 4. Loss and failure rate of Hookpod-minis across experimental and operational trials showing loss/breakage and failures as a percentage of total Hookpod-mini deployments

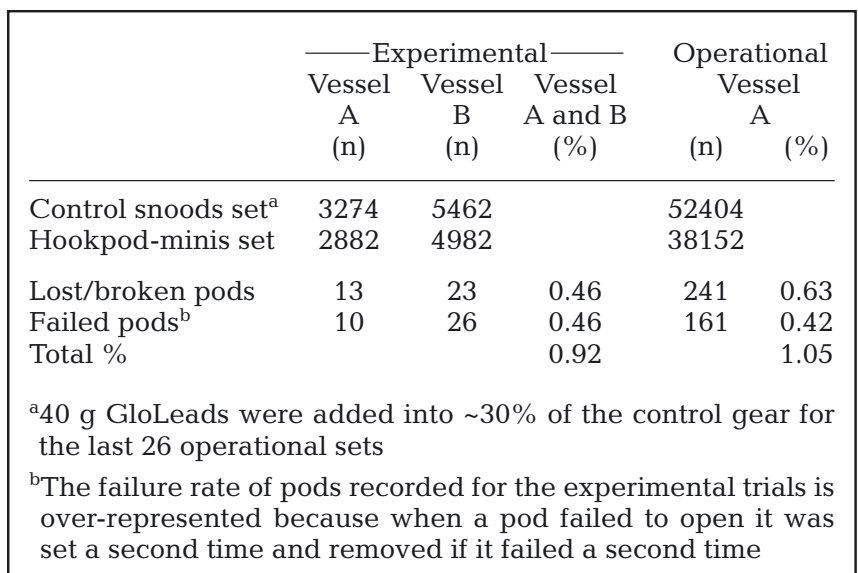

and were $>1 \mathrm{~m}$ deeper at 75 and $100 \mathrm{~m}$ astern of the vessel. However, the sink rate was slower to all 3 threshold depths than for the 3 line weighting configurations, and the Hookpod-minis were $>2 \mathrm{~m}$ shallower than weighted gear at both 75 and $100 \mathrm{~m}$ astern of the vessel. In summary, Hookpod-minis sank faster than unweighted gear and slower than weighted gear of different configurations (Table 5).

\section{DISCUSSION}

\subsection{Fish catch rate}

Although no significant differences in catch rates of target species between treatments for 'Target tuna' and all other family cohorts were identified, the nature of pelagic longline catches and small sample sizes suggest that further investigation and large sample sizes would be necessary to tease out small differences.

\subsection{Sink rate}

The slower sink rate of Hookpod-minis compared to the line weighting configurations we tested is not unexpected as the Hookpod-mini has considerably more volume than a weighted swivel or sliding lead. Sink rate data presented in Table 5 indicate that Hookpod-minis opening at $10 \mathrm{~m}$ provide protection from baited hooks during line setting to a depth greater than that achieved through the combined use of a tori line with $75 \mathrm{~m}$ aerial extent and line weighting of either $38 \mathrm{~g}$ at $0.5 \mathrm{~m}$ from the hook or $60 \mathrm{~g}$ at $1 \mathrm{~m}$ from the hook.

The mechanism by which Hookpods reduce bycatch, i.e. 'de-arming' the hook rather than increasing its sink rate, complicates direct performance comparisons with the more traditional tori line and line weighting approach. The advantages of encapsulating the baited hook to a safe depth under all operational and environmental conditions support the need for a new paradigm of thinking to develop criteria that more fully assess the performance and effectiveness of emerging 'hook-shielding' technology (e.g. Robertson et al. 2013, Baker et al. 2016). These criteria could include all elements of the device's functionality and mode of operation, as well as its overall effectiveness at reducing seabird bycatch.

\subsection{Seabird bycatch}

A single bird returned from each treatment during experimental trials on Vessel B does not provide sufficient data for drawing robust conclusions as to the relative efficacy of the 2 different treatments. To achieve this with bird capture rates alone would require long-term data sets over several vessels, possibly skipper-collected. Alternatively, fishing opera-

Table 5. Mean sink times to 2, 5 and $10 \mathrm{~m}$ depth, and depths at 75 and $100 \mathrm{~m}$ behind the vessel, of time depth recorders deployed on Vessels A, B and C. Standard error is shown in brackets

\begin{tabular}{|c|c|c|c|c|c|c|c|}
\hline \multirow{2}{*}{$\begin{array}{l}\text { Vessel } \\
\text { speed } \\
\text { (knots) }\end{array}$} & \multirow{2}{*}{ Treatment } & \multirow[t]{2}{*}{$\mathrm{N}$} & \multicolumn{5}{|c|}{ - Mean time / depth $( \pm 1 \mathrm{SE})$} \\
\hline & & & $\begin{array}{l}\text { Time to } \\
2 \mathrm{~m}(\mathrm{~s})\end{array}$ & $\begin{array}{l}\text { Time to } \\
5 \mathrm{~m} \mathrm{(s)}\end{array}$ & $\begin{array}{l}\text { Time to } \\
10 \mathrm{~m}(\mathrm{~s})\end{array}$ & $\begin{array}{l}\text { Depth at } 75 \mathrm{~m} \\
\text { astern }(\mathrm{m})\end{array}$ & $\begin{array}{l}\text { Depth at } 100 \mathrm{~m} \\
\text { astern }(\mathrm{m})\end{array}$ \\
\hline A $5.5-6.5$ & Hookpod-mini & 27 & $15(11-20)$ & $28(21-34)$ & $126(60-193)$ & $4.4(3.1-5.7)$ & $6.4(7.9-5.0)$ \\
\hline A $5.5-6.5$ & Unweighted & 31 & $18(13-22)$ & $36(24-48)$ & $127(66-188)$ & $3.4(2.2-4.6)$ & $5.2(6.8-3.6)$ \\
\hline B 7.3 & Hookpod-mini & 23 & $15(11-19)$ & $32(24-40)$ & $71(51-91)$ & $3.3(2.4-4.2)$ & $4.6(3.6-5.7)$ \\
\hline B 7.3 & $60 \mathrm{~g}$ at $1 \mathrm{~m}$ from the hook & 23 & $13(10-16)$ & $22(17-28)$ & $52(33-71)$ & $4.6(3.2-6.1)$ & $6.6(5.2-8.0)$ \\
\hline C 6.5 & Hookpod-mini & 22 & $15(12-17)$ & $28(21-34)$ & $72(52-93)$ & $4.3(3.3-5.3)$ & $5.8(4.3-7.3)$ \\
\hline C 6.5 & $38 \mathrm{~g}$ at $0.5 \mathrm{~m}$ from the hook & 22 & $11(8-14)$ & $19(14-24)$ & $52(26-78)$ & $6.4(5.0-7.8)$ & $8.0(6.3-9.7)$ \\
\hline C 6.5 & $60 \mathrm{~g}$ at $1 \mathrm{~m}$ from the hook & 21 & $11(9-13)$ & $19(15-24)$ & $48(35-62)$ & $6.6(5.1-8.1)$ & $8.1(6.5-9.6)$ \\
\hline
\end{tabular}


tions could be modified (e.g. daylight setting in areas of high overlap) to increase risk to birds, which could result in an unacceptable level of mortality and lack relevance to actual fishing conditions. The fact that the skipper did not use a tori line for some sets because of high winds indicates that Hookpod-minis are a more practical and consistent solution in all weather conditions. This in itself is an important consideration when there is currently no method for measuring levels of compliance with tori line regulations or the distance from the hook at which sliding weights are placed.

It is important to note that 2 of the 3 mortalities recorded on Hookpod-minis during the long-term operational trials were caused by entanglement in the snoods and not due to seabirds accessing the baited hook. Although not tested statistically due to low sample size, the entanglement rate on Hookpodmini snoods was lower than on control snoods and suggests that the loop formed in the snood when the Hookpod is loaded (see Fig. 2 in Sullivan et al. 2018) does not cause an increase in seabird entanglement.

The capture of a total of 4 birds on Hookpod-mini snoods ( 2 of which were entanglements, not hookups) compared to 14 on control snoods across all trials indicates that Hookpod-minis do not eliminate seabird bycatch, but they can result in low levels of bycatch over long-term fishing operations, including the southern bluefin tuna season when seabird interactions occur at their highest rate. Our data show that Hookpod-minis provide protection for hooks during line setting to a greater depth than bycatch mitigation methods currently in use and may result in low seabird mortality.

As is the case for most seabird bycatch mitigation options for pelagic longline fisheries, Hookpod-minis target the highest risk setting period of fishing, but bycatch may occur during fishing if lines are brought close to the surface during the soak or during the haul. Bycatch mitigation options for these other periods of the fishing operation remain an active research area.

The combination of line weighting and tori lines has been shown to be an effective solution to reduce seabird bycatch in pelagic longline fisheries under experimental conditions (Melvin et al. 2014). However, under operational conditions, the effectiveness of this combination is highly dependent upon the assumption of an average sink rate and the assumption that tori lines achieve their maximum effectiveness over their prescribed aerial extent (e.g. frequently 75 to $100 \mathrm{~m}$ astern). On-board Vessel B tori lines were not deployed on the final 4 sets (out of 12) due to an entanglement with the fishing gear and tori line in windy conditions on the seventh set. It has been well documented that such entanglements reduce both the deployment rate and effectiveness of tori lines once they are deployed (Domingo et al. 2017). Currently, there are low levels of at-sea observer coverage, typically $<5 \%$ (Allain et al. 2012), and even lower uptake rates of electronic monitoring on the world's pelagic longline fisheries. In this environment, the use of Hookpod-minis would have the advantages of a single-stop mitigation that is incorporated into the gear and suitability for use under all operational and environmental conditions.

\subsection{Replacement rate and utility of Hookpod-minis}

The replacement rate of Hookpod-minis, which includes all forms of malfunctioning, lost and damaged pods, during the experimental trials on vessels $\mathrm{A}$ and $\mathrm{B}$ were identical and represented a total replacement rate of $0.92 \%$ (Table 4 ). This is similar to the rate of $1.02 \%$ recorded over the course of the 10 mo operational sampling period, which suggests that a replacement rate of $\sim 1 \%$ could be considered a reliable long-term/'real world' estimate of durability. Based on a cost-benefit analysis of the economics of the Hookpod-mini for fishermen, Sullivan et al. (2018) established an a priori threshold replacement rate of $\sim 1 \%$ for Hookpod-LED and Hookpod-minis, and this has now been established for both the Hookpod-mini (Table 4) and the Hookpod-LED (Sullivan et al. 2018).

The Hookpod-mini has the potential to remove the need for the use of tori lines and/or weighted swivels. Other potential benefits include removal of daylight setting restrictions and a general simplification of seabird bycatch mitigation options by replacing several measures with a single technology.

\section{CONCLUSION}

The combination of short-term experimental and long-term operational data presented here indicates that Hookpod-minis do not reduce the catch rate of target species, are operationally simple for fishermen to fit into their daily routines, and have the potential to reduce seabird bycatch rates to low levels. The extended 10 mo period of use on 1 vessel clearly indicates the suitability of Hookpod-minis for continued use in commercial fishing operations beyond short experimental trial periods. Although experimental 
results did not provide a statistically significant difference in seabird capture rates, we conclude that Hookpod-minis as a stand-alone mitigation measure provide consistent protection of hooks to a greater depth during line setting than current bycatch mitigation measures, including the combination of line weighting and tori lines.

Conflict of interest. Hookpod Limited staff provided assistance with the provision of the hardware. B. Sullivan assisted us with planning of these trials and commented on the manuscript. He is a director of Hookpod Limited and works under contract for Hookpod Limited. J. Potts (The Analytical Edge Statistical Consulting) was hired by Hookpod Limited as an independent statistical expert to conduct all the data analysis presented in this manuscript. D. Goad and I. Debski have no conflicting interests.

Acknowledgements. The authors would like to thank the vessel owners, skippers and crew involved who contributed their time, patience and advice throughout the trials. Hookpod Ltd provided the pods for the trials, and Ben Sullivan, Becky Ingham, Ben and Pete Kibel (Hookpod, Fishtek Marine) provided valuable support throughout. The Ministry for Primary Industries, New Zealand provided advice and support and organised the special permit (654) to operate without a tori line. Funding for D.G., including at-sea work, was provided by the Department of Conservation's Conservation Services Programme through levies on quota holders of the relevant fish stocks.

\section{LITERATURE CITED}

Allain V, Nicol S, Polovina J, Coll M and others (2012) International workshop on opportunities for ecosystem approaches to fisheries management in the Pacific Ocean tuna fisheries. Rev Fish Biol Fish 22:29-33

Baker GB, Candy SG, Rollinson D (2016). Efficacy of the 'Smart Tuna Hook' in reducing bycatch of seabirds in the South African pelagic longline fishery. 7th Mtg Agreement on the Conservation of Albatrosses and Petrels SBWG, Inf 7, 2-4 May 2016La Serena, Chile

BirdLife International (2015). One in eight of all bird species

Editorial responsibility: Austin Gallagher,

Herndon, Virginia, USA is threatened with global extinction. BirdLife State of the World's Birds. www. birdlife.org/datazone/sowb/case study/106 (accessed 18 Sept 2019)

* Croxall JP, Butchart SH, Lascelles B, Statterfield AJ, Sullivan BJ, Symes A, Taylor P (2012) Seabird conservation status, threats and priority actions: a global assessment. Bird Conserv Int 22:1-34

* Domingo A, Jiménez S, Abreu M, Forselledo R, Yates O (2017) Effectiveness of tori line use to reduce seabird bycatch in pelagic longline fishing. PLOS ONE 12: e0184465

* Gilman E, Boggs C, Brothers N (2003) Performance assessment of an underwater setting chute to mitigate seabird bycatch in the Hawaii pelagic longline tuna fishery. Ocean Coast Manage 46:985-1010

*Melvin EF, Guy TJ, Read LB (2013) Reducing seabird bycatch in the South African joint venture tuna fishery using bird-scaring lines, branch line weighting and nighttime setting of hooks. Fish Res 147:72-82

* Melvin EF, Guy TJ, Read LB (2014) Best practice seabird bycatch mitigation for pelagic longline fisheries targeting tuna and related species. Fish Res 149:5-18

New Zealand Gazette (2014) Fisheries (Seabird mitigation measures-surface longlines). Circular 2014 68:1935

Robertson G, Candy SG, Wienecke B, Lawton K (2010) Experimental determinations of factors affecting the sink rates of baited hooks to minimize seabird mortality in pelagic longline fisheries. Aquat Conserv 20:632-643

Robertson G, Candy SG, Hall S (2013) New branch line weighting regimes to reduce the risk of seabird mortality in pelagic longline fisheries without affecting fish catch. Aquat Conserv 23:885-900

Robertson G, Candy SG (2014) Does propeller turbulence affect the sink rate of baited hooks and their availability to seabirds in pelagic longline fisheries? Aquat Conserv 24:179-191

* Robertson G, Ashworth P, Ashworth P, Carlyle I, Candy S (2015) The development and operational testing of an underwater bait setting system to prevent the mortality of albatrosses and petrels in pelagic longline fisheries. Open J Mar Sci 5:52452

* Ryan PG, Watkins BP (2002) Reducing incidental mortality of seabirds with an underwater longline setting funnel. Biol Conserv 104:127-131

* Sullivan BJ, Kibel B, Kibel P, Yates O and others (2018) At-sea trialling of the Hookpod: a 'one-stop' mitigation solution for seabird bycatch in pelagic longline fisheries. Anim Conserv 21:159-167

Submitted: September 21, 2018; Accepted: February 26, 2019 Proofs received from author(s): April 19, 2019 